\title{
PARASITÓIDES ASSOCIADOS À LAGARTA-ENROLADEIRA Bonagota cranaodes (MEYRICK, 1937) (LEPIDOPTERA: TORTRICIDAE) NA CULTURA DA MACIEIRA
}

\section{PARASITOIDS ASSOCIATED WITH Bonagota cranaodes (MEYRICK, 1937) (LEPIDOPTERA: TORTRICIDAE) IN APPLE ORCHARDS}

\author{
Marcos Botton $^{1}$ OctávioNakano $^{2}$ Adalécio Kovaleski $^{1}$
}

\section{- NOTA -}

\section{RESUMO}

\begin{abstract}
Os parasitóides associados à lagarta-enroladeira-damacieira Bonagota cranaodes e o índice de parasitismo em pomares comerciais foram avaliados em Vacaria, RS $\left(28^{\circ} 30^{\circ} \mathrm{S} / 50^{\circ} 54 \mathrm{~W}\right)$. A coleta das fases de desenvolvimento do inseto foi realizada no período de janeiro a junho de 1997. Lagartas de $\boldsymbol{B}$. cranaodes foram parasitadas por insetos da família Braconidae (Apanteles sp e Earinus sp.) e Ichneumonidae (Itoplectis brasiliensis), sendo esta, a espécie mais freqüente, com $51,7 \%$ dos indivíduos coletados. $O$ índice médio de parasitismo foi de $1,7 \%$ com máximo de 6,3\% na primeira quinzena de maio. Não foram encontrados parasitóides associados à fase de ovo de B. cranaodes. Com base nestas informações, verificou-se que o parasitismo não é um fator importante de mortalidade da lagarta-enroladeira nos pomares comerciais de macieira.
\end{abstract}

Palavras-chave: lagarta-enroladeira-da-macieira, controle biológico.

\section{SUMMARY}

A survey of parasitoids associated with apple leafroller Bonagota cranaodes and the level of parasitism was evaluated in commercial apple orchards in Vacaria, RS, Brazil $\left(28^{\circ} 30^{`} \mathrm{~S} / 50^{\circ} 54 \mathrm{~W}\right)$ by collecting eggs, larvae and pupae from

\begin{abstract}
January to June, 1997. Three species of parasitoids (Apanteles $s p$, Earinus sp. and Itoplectis brasiliensis) were found associated with B. cranaodes larvae and pupae. I. brasiliensis was the most frequent specie, with $51.7 \%$ of insects collected. The average of parasitism was $1.7 \%$, with maximum of $6.7 \%$ in the first week of May. No parasitoids were found associated with B. cranaodes eggs. Mortality caused by parasitoids was not considered an important agent of control of the apple leafroller in commercial apple orchards of southern Brazil.
\end{abstract}

Key words: biological control, Trichogramma.

A lagarta-enroladeira Bonagota cranaodes é uma das principais pragas da cultura da macieira na região sul do Brasil. O conhecimento dos fatores bióticos e abióticos que afetam a flutuação populacional de uma determinada praga é fundamental para o desenvolvimento do manejo integrado. Dentre os fatores bióticos responsáveis pela regulação das populações de pragas, os parasitóides destacam-se entre os de maior importância.

${ }^{1}$ Engenheiro Agrônomo, Doutor, Pesquisador EMBRAPA Uva e Vinho, CP 130, 95.700-000, Bento Gonçalves, RS. E-mail: marcos@cnpuv.embrapa.br. Autor para correspondência.

${ }^{2}$ Engenheiro Agrônomo, Doutor, Professor Escola Superior de Agricultura Luiz de Queiróz, Universidade de São Paulo, Departamento de Entomologia. 
No caso da lagarta-enroladeira, as espécies de parasitóides associadas ao inseto são praticamente desconhecidas. Até o momento, foi realizada somente uma coleta de lagartas e pupas em Vacaria, RS, no mês de abril, verificando-se que dos insetos coletados somente 1,2\% encontrava-se parasitado (EIRAS et $\boldsymbol{a l}$. , 1992). Os parasitóides encontrados pertencem às famílias Ichneumonidae e Chalcididae. LORENZATTO (1988) relatou como inimigos naturais da lagarta-enroladeira predadores das famílias Anthocoridae, Forficulidae e Vespidae e o parasitóide de ovos do gênero Trichogramma. ORTH et al. (1986) citam que o inseto é parasitado por microhimenópteros e Tachinidae.

Em face da carência de informações do efeito dos inimigos naturais sobre $\boldsymbol{B}$. cranaodes na cultura da macieira, este trabalho foi realizado visando a conhecer os parasitóides e quantificar o parasitismo natural em dois pomares comerciais de Vacaria, RS.

A avaliação dos inimigos naturais de $\boldsymbol{B}$. cranaodes foi realizada coletando-se posturas, lagartas e pupas encontradas em dois pomares comerciais de macieira com aproximadamente cinco ha cada, da cultivar Fuji, plantados em 1988, localizados em Vacaria, RS (28 $\left.30^{\circ} \mathrm{S} / 50^{\circ} 54 \mathrm{~W}\right)$. Nos dois pomares, os tratamentos fitossanitários foram realizados, conforme calendário do produtor, a cada 8 e 15 dias para fungicidas e inseticidas, respectivamente.

No período de janeiro a junho de 1997 , semanalmente, em cada pomar, duas pessoas permaneciam aproximadamente quatro horas coletando ao acaso as fases de desenvolvimento de B. cranaodes presentes em plantas de macieira e, na vegetação do pomar, em plantas hospedeiras do inseto (KOVALESKI et al., 1998). As fases encontradas foram coletadas junto com as folhas sendo levadas ao Laboratório de Entomologia da Embrapa Uva e Vinho, Estação Experimental de Vacaria, onde foi realizada a triagem do material. No laboratório, as posturas, lagartas e pupas coletadas nos dois pomares foram contadas, transferidas para tubos de ensaio $(2,5 \mathrm{~cm}$ de diâmetro $\mathrm{X} 8,5 \mathrm{~cm}$ de altura) contendo dieta artificial (PARRA et al., 1995) e mantidas na temperatura de $25 \pm 2^{\circ} \mathrm{C}$ com fotofase de 14 horas.

As posturas foram acompanhadas diariamente até a eclosão das lagartas, avaliando-se a viabilidade dos ovos. As lagartas e pupas foram mantidas nos tubos de ensaio até a emergência dos adultos de $\boldsymbol{B}$. cranaodes ou dos parasitóides associados. As espécies de parasitóides coletadas foram fixadas em álcool $70 \%$ sendo identificados pela professora Maria Angélica Penteado-Dias, da Universidade Federal de São Carlos, e pelo Dr. Charles Porter, da Universidade da Flórida. Espécies testemunha estão depositados no Museu de Entomologia da Universidade de São Carlos. Para cálculo do índice de parasitismo no período de janeiro a junho de 1997 , dividiuse o número total de parasitóides obtidos nos dois pomares pelo total de lagartas e pupas coletadas, a intervalos quinzenais. A freqüência refere-se à percentagem de indivíduos de uma espécie de parasitóide em relação ao total de insetos coletados.

No período de avaliação (janeiro a junho) foram coletadas 120 posturas de $\boldsymbol{B}$. cranaodes, não se encontrando parasitóides associados a esta fase de desenvolvimento do inseto. Em todas as avaliações, a viabilidade dos ovos foi superior a $90 \%$. A busca de parasitóides que atacam a fase de ovo tem sido constante em diferentes culturas, pois permite controlar as pragas antes do seu estabelecimento nas plantas, previamente à ocorrência dos danos. No caso de B. cranaodes, embora LORENZATTO (1988) cite a ocorrência do parasitismo de ovos por Trichogramma e, no Uruguai, a espécie seja um importante inimigo natural do inseto (BASSO et al., 1998), neste trabalho a espécie não foi encontrada. A ausência de Trichogramma parasitando posturas da lagarta-enroladeira pode ser atribuída à sensibilidade do inseto aos inseticidas fosforados empregados nos pomares comerciais de macieira (HASSAN $\boldsymbol{e t} \boldsymbol{a l}$., 1988). Nesse sentido, é importante que a busca de parasitóides associados à fase de ovo da lagartaenroladeira seja continuada, pois a postura fica exposta na parte superior das folhas por um período geralmente superior a 7 dias, permitindo que ocorra o parasitismo. Além disso, existem fases de desenvolvimento da cultura da macieira como a floração e após a colheita, quando não são utilizados inseticidas químicos, o que permitiria a liberação inudativa dos parasitóides. Exemplos neste sentido vêm sendo realizados nos Estados Unidos com a espécie Choristoneura rosaceana (Lepidoptera: Tortricidae) na cultura da macieira com resultados promissores (LAWSON et al., 1997).

Com relação às demais fases de desenvolvimento de $\boldsymbol{B}$. cranaodes, no período de avaliação foram coletados 1.720 insetos (1389 lagartas e 331 pupas), sendo que destes somente 29 encontravam-se parasitados (Tabela 1). Três espécies de parasitóides foram encontradas associadas à lagarta-enroladeira, sendo todas pertencentes à ordem Hymenoptera .

A espécie Itoplectis brasiliensis foi a mais freqüente, sendo responsável por praticamente 51,7\% do parasitismo. Earinus sp e Apanteles sp responderam por 20,7 e $27,6 \%$ do total, respectivamente (Tabela 2). Por outro lado, foi observada uma sazonalidade na ocorrência dos

Tabela 1 - Parasitóides associados à lagarta-enroladeira Bonagota cranaodes em pomares comerciais de macieira em Vacaria, RS.

\begin{tabular}{lcccc}
\hline Parasitóide & Família & $\begin{array}{c}\text { Fase de } \\
\text { emergência }\end{array}$ & $\begin{array}{c}\text { Localização } \\
\text { no hospedeiro }\end{array}$ & $\begin{array}{c}\text { Indivíduos } \\
\text { por inseto }\end{array}$ \\
\hline $\begin{array}{l}\text { Apanteles } \mathrm{sp} \\
\text { Earinus } \mathrm{sp}\end{array}$ & Braconidae & Lagarta & Interna & Solitário \\
brasiliensis & Braconidae & Pupa & Interna & Solitário \\
& Ichneumonidae & Pupa & Interna & Solitário \\
\hline
\end{tabular}


Tabela 2 - Parasitóides associados à lagarta-enroladeira Bonagota cranaodes em pomares comerciais de macieira em Vacaria, RS, no período de janeiro a junho de 1997.

\begin{tabular}{|c|c|c|c|c|c|c|}
\hline \multirow{2}{*}{$\begin{array}{c}\text { Data de } \\
\text { amostragem/ } \\
\text { quinzena }\end{array}$} & \multirow{2}{*}{$\begin{array}{c}\mathrm{N}^{\mathrm{o}} \text { coletado } \\
\text { (lagarta + pupas) }\end{array}$} & \multirow[t]{2}{*}{$\mathrm{N}^{\mathrm{o}}$ parasitóides } & \multirow{2}{*}{$\begin{array}{c}\text { Parasitismo } \\
(\%)\end{array}$} & \multicolumn{3}{|c|}{ Parasitóides (\%) } \\
\hline & & & & Apanteles sp & Earinus sp & $\begin{array}{l}\text { Itoplectis } \\
\text { brasiliensis }\end{array}$ \\
\hline Janeiro/1 & 200 & 3 & 1,5 & 66 & 34 & - \\
\hline Janeiro/2 & 170 & 2 & 1,2 & 50 & 50 & - \\
\hline Fevereiro/1 & 187 & 1 & 0,5 & 100 & - & - \\
\hline Fevereiro/2 & 196 & 1 & 0,5 & 100 & - & - \\
\hline Março/1 & 153 & 2 & 1,3 & - & 50 & 50 \\
\hline $\mathrm{Março/2}$ & 174 & 2 & 1,2 & 100 & - & - \\
\hline Abril/1 & 156 & 2 & 1,3 & - & - & 100 \\
\hline Abril/2 & 166 & 2 & 1,3 & - & - & 100 \\
\hline Maio/1 & 119 & 4 & 3,4 & 25 & - & 75 \\
\hline Maio/2 & 79 & 5 & 6,3 & - & 40 & 60 \\
\hline Junho/1 & 91 & 4 & 4,4 & - & 25 & 75 \\
\hline Junho/2 & 29 & 1 & 3,4 & - & - & 100 \\
\hline
\end{tabular}

parasitóides predominando o Apanteles sp. até março e Itoplectis a partir deste período (Tabela 2).

A porcentagem de parasitismo variou de 0,5 a $1,5 \%$ no período de janeiro a abril até atingir $6,3 \%$ em maio, quando se verificou o maior número de insetos parasitados (Tabela 2). Os índices de parasitismo observados a partir de maio foram maiores provavelmente devido ao fim das pulverizações de inseticidas que ocorre a partir do início da colheita da cultivar Fuji em meados de abril.

O parasitismo encontrado no mês de abril de $1,3 \%$ foi muito próximo aos $1,2 \%$ relatados por EIRAS et al., 1992, para o mesmo período. Considerando todo o intervalo de avaliação, a média de parasitismo da lagarta-enroladeira foi de 1,7\%, devendo-se salientar que este índice pode estar subestimado, pois os insetos foram retirados do campo e levados ao laboratório, reduzindo o período de exposição aos inimigos naturais. Mesmo assim, verifica-se que o valor foi baixo. Considerando-se a situação atual de manejo dos pomares avaliados, os parasitóides não devem ser considerados como fator importante de mortalidade do inseto.

Nesse sentido, acredita-se que a liberação de espécie introduzida ou nativa encontraria recursos disponíveis (posturas, lagartas, pupas) que poderiam levar a uma redução no tamanho final da população de B. cranaodes nos pomares de macieira, principalmente se as liberações forem realizadas após a colheita ou durante a floração, quando não são aplicados inseticidas nos pomares. Por isso, é importante que sejam estudados a biologia, a dinâmica populacional e os hospedeiros alternativos dos parasitóides nativos associados à lagartaenroladeira visando a implementar táticas de conservação e incremento das populações nos pomares comerciais, principalmente através do emprego de inseticidas seletivos.

\section{REFERÊNCIAS BIBLIOGRÁFICAS}

BASSO, C., GRILLE, G., POMPANON, F., et al. Comparacion de los caracteres biológicos y etológicos de Trichogramma pretiosum y de T. exiguum (Hymenoptera: Trichogrammatidae). Revista Chilena de Entomologia, v.25, p. 45-53, 1998.

EIRAS, A.E., KOVALESKI, A., VILELA, E.F., et $\boldsymbol{a l}$. Observações preliminares sobre a ocorrência do parasitismo natural na lagarta-enroladeira Phtheochroa cranaodes (Meyrick) (Lepidoptera : Tortricidae) em pomares de macieira em Vacaria (RS). In: SIMPÓSIO DE CONTROLE BIOLÓGICO, 3, 1992, Águas de Lindóia. Resumos... Águas de Lindóia : Embrapa, 1992. p. 304.

HASSAN, S.A., KOHLER, E., ROST, W.M. Mass production and utilization of Trichogramma: 10. Control of the codling moth Cydia pommonella and the summer fruit tortrix moth Adoxophyes orana (lepidoptera : Tortricidae). Entomophaga v. 33, p. 413-420, 1998.

KOVALESKI, A., BOTTON, M., EIRAS, A.E., et al. Lagartaenroladeira da macieira: bioecologia e controle. Bento Gonçalves : Embrapa, CNPUV, 1998. 22 p. (Embrapa. CNPUV. Circular Técnica, 24).

LAWSON, D.S., NYROP, J.P., REISSIG, W.H. Assays with comercially produced Trichogramma (Hymenoptera : Trichogrammatidae) to determine suitability for obliquebanded leafroller (lepidoptera : Trotricidae) control. Environmental Entomology, v. 26 n. 3, p. 684-693, 1997.

LORENZATO, D. Lepidópteros nocivos em frutíferas rosáceas no sul do Brasil. Ipagro Informa, v. 31, p. 71-77, 1988.

ORTH, A.I., RIBEIRO, L.G., REIS FILHO, W. Manejo de pragas. In: EMPRESA CATARINENSE DE PESQUISA AGROPECUÁRIA. Manual da cultura da macieira. Florianópolis ; Empasc, 1986. p.341-379.

PARRA, J.R.P., EIRAS, A.E., HADDAD, M.L., et al. Técnica de criação de Phtheochroa cranaodes Meyrick (Lepidoptera : Tortricidae) em dieta artificial. Revista Brasileira de Biologia, v.55, n.4, p.537-543, 1995. 